\title{
Pueblos, libre determinación y pluralismo jurídico. Aproximación sociojurídica crítica en Puelmapu y el Principat de Catalunya ${ }^{1}$
}

\author{
Dino Di Nella² \\ Victoria Ibáñez ${ }^{3}$
}

${ }^{1}$ Este trabajo es una versión actualizada efectuada por Dino Di Nella y Victoria Ibáñez, de un texto inicialmente redactado en el marco del Proyecto PI-UNRN40-C-803, de la Sede Atlántica de la Universidad Nacional de Río Negro, y el Programa Memorias, Pueblos y Estados del Centro de Investigación en Derecho Crítico de la Facultad de Ciencias Jurídicas y Sociales de la Universidad Nacional de La Plata, que solo puede ser concebido como parte de una autoría y construcción colectiva y en marcha de su equipo de trabajo, integrado por Pablo Cabral y Fernando Maitini (del CIDERCRIT de la Facultad de Ciencias Jurídicas y Sociales de la Universidad Nacional de La Plata; Patricia Giordana y Julián Arribas, de la Sede Atlántica de la Universidad Nacional de Río Negro; Pablo Casals y Elisabet Almeda, del Col-lectiu de Solidaritat amb els Països Catalans; Alicia Ortiz y Camila Loggiacco, de la Fundación Adalquí; y Luis D’Alfonso y Kevin Hetherington, estudiante investigador de la Universidad Nacional de Río Negro.

2 Investigador responsable del Proyecto PI-UNRN-40-C-803, Sede Atlántica de la Universidad Nacional de Río Negro. Co-responsable del Programa Memorias, Pueblos y Estados, Centro de Investigación en Derecho Crítico, Facultad de Ciencias Jurídicas y Sociales, Universidad Nacional de La Plata.

3 Docente Universidad Nacional del Comahue. Co-responsable del Programa Memorias, Pueblos y Estados, Secretaría de Relaciones Institucionales, Facultad de Ciencias Jurídicas y Sociales, Universidad Nacional de La Plata.

B CLIVATGE, número 8

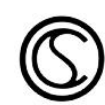


Resumen: Este texto aborda las tendencias actuales de los procesos de descolonizaciones, autodeterminaciones y/o independencias de los pueblos-nación marginalizados de los Estados centrales del capitalismo mundial, presentando los casos del pueblo-nación mapuche y el pueblo-nación catalán como forma de aproximación a la cuestión. Para ello, se analiza el derecho de libre determinación (o a la existencia diferenciada) de los pueblosnación sin Estado propio, en Estados plurinacionales o bajo Estados opresores, en el contexto de los actuales debates y teorizaciones sobre los pueblos y los Estados plurinacionales, desde una perspectiva de pluralismo jurídico crítico. El trabajo se efectúa a instancias del Programa Memorias, Pueblos y Estados, dependiente de la Secretaría de Relaciones Institucionales y radicado en el Centro de Investigación en Derecho Crítico de la Facultad de Ciencias Jurídicas y Sociales de la Universidad Nacional de La Plata, y el patrocinio y apoyo del Colectivo de Acción Jurídica, Social y Cultural Copolis-Adalquí (Sede Atlántica de la Universidad Nacional de Río Negro/Fundación Adalquí), el Col-lectiu de Solidaritat amb els PaïsosCatalans, y el Grupo Interuniversitario Copolis. Bienestar, Comunidad y Control Social (Universidad de Barcelona).

Palabras clave: pluralismo jurídico, pueblos, naciones, estados, libre determinación

B CLIVATGE, número 8

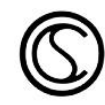


Abstract: This paper is about present trends in de-colonization, self-determination and/or independence processes of marginalized peoples-nations in the central states of world capitalism, and it deals with the cases of the Mapuche and the Catalan peoples-nations as a way of approaching the issue. To do so, we analyse the right to free self-determination-or to separate existence-of peoples-nations without an independent state, in plurinational states of under oppressive states, in the context of the present debates and theorisations about peoples and plurinational states, from the perspective of critical juridical pluralism. This study was carried out under the auspices of the Memory, Peoples and States Programme by the Secretariat of Institutional Relationships at the Centre for Research in Critical Law of the Faculty of Law and Social Science of the National University of La Plata, and under the sponsorship and support of the CopolisAldaquí Group for Juridical, Social and Cultural Action (Atlantic Delegation of the National University of Río Negro / Adalquí Foundation), the Solidarity with the Catalan Countries Group, and the Copolis Inter-University Group: Welfare, Community and Social Control (University of Barcelona).

Keywords: juridical pluralism, peoples, nations; states, free selfdetermination

B CLIVATGE, número 8

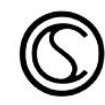


Resum: Aquest text aborda las tendències actuals dels processos de descolonitzacions, autodeterminacions i/o independències dels pobles-nació marginats dels Estats centrals del capitalisme mundial, tot presentant els casos del poble-nació maputxe i el poble-nació català com a forma d'aproximació a la qüestió. A aquest fi, s'hi analitza el dret de lliure determinació (o a l'existència diferenciada) dels pobles-nació sense Estat propi, en Estats plurinacionals o sota Estats opressors, en el context dels debats i teoritzacions actuals sobre els pobles i els Estats plurinacionals, des d'una perspectiva de pluralisme jurídic crític. El treball es realitza a instàncies del Programa Memorias, Pueblos y Estados, dependent de la Secretaría de Relaciones Institucionales y radicat en el Centro de Investigación en Derecho Crítico de la Facultad de Ciencias Jurídicas y Sociales de la Universidad Nacional de La Plata, i amb el patrocini i el suport del Colectivo de Acción Jurídica, Social y Cultural Copolis-Adalquí (Seu Atlàntica de la Universidad Nacional de Río Negro/Fundación Adalquí), el Col·lectiu de Solidaritat amb els Països Catalans, i el Grup Interuniversitari Copolis. Benestar, Comunitat i Control Social (Universitat de Barcelona).

Paraules clau: pluralisme jurídic, pobles, nacions, Estats, lliure determinació

B CLIVATGE, número 8

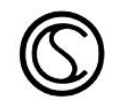


El análisis y estudio de los pueblos y naciones sin estado propio, su derecho a la libre determinación y el pluralismo jurídico, ha ido evolucionando sostenida pero lentamente, desde finales del siglo XIX, si bien a mediados del Siglo XX empezó a tener una mayor significación, sobre todo en los análisis del derecho internacional público, la sociología política y los abordajes de la memoria colectiva y la identidad. No obstante, es a partir de la primera década del siglo XXI, que este abordaje se ha expandido acelerada e intensamente en casi todos los países del entorno.

El conjunto de los antecedentes y aportes del equipo de este trabajo en el marco de diversas investigaciones ${ }^{4}$, nos permite afirmar que a nivel comparado e internacional, cabría destacar un crecimiento de los estudios, que podemos agrupar en cinco ejes centrales (Di Nella, Giordana, Loggiacco, 2019; Di Nella, 2018a, 2006, 2011; ver selección bibliográfíca de los principales autores y autoras de actualidad, efectuada por el equipo de este trabajo, en https://www.adalqui.org.ar/bibliografia/ , rec. 30/04/2020).):

a) las reflexiones más teóricas sobre sus significados, percepciones, racionalidades, dilemas analíticos, construcciones jurídicas, discursos o identidades;

b) las políticas públicas y legislativas enmarcadas en los regímenes de organización territorial de los estados;

4 I+D INFOJUS-2013 “Derechos Humanos y Desigualdades Sociales"; 2017UNRN-40-C-649 "Dinámicas de género, familia y hábitat en mujeres urbanas mapuche"; 2017-RICIP-00015 "Conflicto en Catalunya y represión política"; y 2019-UNRN-40-C-803 "Pueblos, estados y libre determinación. Estudio sociojurídico de Puelmapu y el Principat de Catalunya"

B CLIVATGE, número 8

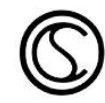


c) los enfoques desde la génesis de los movimientos de liberación nacional como eje central del análisis;

d) los estudios de pobreza y exclusión social estructurales; y

e) las autobiografías o historias de vida de luchadores y luchadoras sociales por la liberación de sus pueblos

Desde esa producción académica, puede sostenerse que las principales aproximaciones a la noción de pueblo, se han vinculado a su configuración y alcance como sujeto colectivo de derechos, en tanto que pueblos "coloniales", "sometidos a dominación extranjera", "movimientos de liberación nacional", "conjunto de habitantes de un Estado", "grupo diferenciado dentro de un Estado", "grupo étnico-cultural", "minoría nacional", y pueblo "indígena", entre otras. Todas ellas, derivadas en gran medida, de la Carta, normas y resoluciones de las Naciones Unidas y sus órganos, tales como la resolución 1541 (XV) y resolución 1541 (XV), de 1960; la resolución 2625 (XXV), de 1970, el Pacto Internacional de Derechos Civiles y Políticos, de 1966, los Convenios 107 (1957) y 169 (1989) de la OIT, y las declaraciones de derechos humanos, como la de los pueblos indígenas y tribales (2007). Tanto los/las cientistas sociales, como los movimientos sociales vinculados a los grupos étnico-culturales y los Estados y entidades multilaterales, han tratado de hacer valer sus respectivas concepciones de "los pueblos".

En particular, esto se observa mas claramente, en los pueblos naciones que no gozaron del reconocimiento de sus derechos a y/o ejercicio de la autodeterminación, por ser pueblos bajo colonialismo interno o intracontinental (y no ultramarino) de

B CLIVATGE, número 8

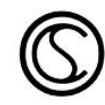


pueblos-naciones en estados ya constituidos. Y aún así, pueden distinguirse dentro de éstos, a los pueblos indígenas de Abya YalaAmerindia (a los que suele reconocérsele el estatuto de pueblos y su derecho a la autodeterminación interna dentro de un estado; como el pueblo nación mapuche) de los pueblos de territorios continentales colindantes de los pueblos hegemónicos de los estados europeos coloniales (su estatuto es el de una unidad regional o minoría nacional más; como el pueblo nación catalán).

Ello permite observar una nueva disquisición sociojurídica, referidas a la libre determinación externa e interna. La libre determinación externa, se refiere al derecho de los pueblos a determinar libremente su lugar en la comunidad internacional de Estados, de acuerdo con el principio de igualdad soberana, pudiendo decidir la formación de un Estado independiente, la libre asociación o integración en un Estado ya existente, o la adquisición de cualquier otro estatuto político libremente decidido por la población. La interna, por su parte, define el derecho de los pueblos a decidir su organización política, perseguir su desarrollo cultural, social y económico, preservar su identidad, y participar, a todos los niveles, en la dirección de los asuntos públicos que les afectan, pudiendo decidir la formación de cualquier estatuto político libremente decidido por la población (confederación, federación, autonomismo, asimetría competencial, unitarismo, etc.), siempre que sea dentro de un estado ya constituido, y de manera consensuada con la población del mismo (Di Nella, 2019). La solución pretendidamente paradigmática -y generalmente concebida jurídicamente-, reconoce el derecho de 
autodeterminación interna en toda su extensión a todos los pueblos, limitando a casos muy estrictos el ejercicio de la autodeterminación externa. La posibilidad -en todo caso, de carácter excepcional- de que estos pueblos ejerzan la vertiente externa de la libre determinación, separándose del Estado al que se encuentran subordinados, correspondería cuando el ejercicio de la autodeterminación interna sea imposible porque el pueblo sufre una persecución o discriminación extrema y sistemática y no parezca existir una solución pacífica factible.

Hay interpretaciones más estrictas o laxas sobre cuándo se da esta situación, según las cuales, habría casos en dónde seguro que sí correspondería, otros en los que de ninguna manera correspondería, y otros casos fronterizos, grises, más difíciles de precisar. Así, existe un consenso internacional que lo aprecia en los regímenes racistas, como el apartheid sudafricano. Igualmente, no se lo aprecia en el caso de minorías nacionales radicadas en razón de flujos migratorios en territorios con los que no habían tenido relación histórica, como las minorías nacionales desplazadas a territorios ultramarinos respecto de su origen. Y entre las zonas fronterizas, que merecen ser analizadas caso por caso, se encuentran aquellos en donde los pueblos naciones no pueden viabilizar su autodeterminación interna dentro de un estado, a raíz del bloqueo de las vías institucionales para el consentimiento libre e informado del pueblo en cuestión sobre la definición política de su futuro, debido a la acción u omisión del respectivo estado, es decir, en regímenes de democracias débiles, delegativas, poco 
representativas de la pluralidad social y nacional, y sin mecanismos institucionales adecuados de participación y decisión directa.

Son estas zonas grises y los estados y pueblos naciones que están frente a esta realidad, lo que despierta mayor interés. En cada uno de los continentes, son numerosos. Varios de estos pueblos, se han nucleado en la Organización de Naciones y Pueblos No Representados (Unrepresented Nations and Peoples Organization, UNPO, por su sigla en inglés), que es una organización internacional cuyos miembros son poblaciones indígenas, minorías y habitantes de territorios no soberanos u ocupados. La UNPO cuenta con casi 50 pueblos miembros (y otros tantos dejaron de serlo a partir de que lograron sus estados, después de su independencia y reconocimiento en las Naciones Unidas; https://unpo.org; rec. 3004-2020). La autodeterminación de los pueblos-naciones, la democracia, la no violencia, el ambientalismo y los derechos humanos, son los cinco principios centrales de la organización.

Dos de estos pueblos-naciones, son el pueblo mapuche y el pueblo catalán, los cuales constituyen los estudios de caso que aquí se presentan.

El pueblo-nación Mapuche es uno de los pueblos milenarios del sur de Abya Yala-Amerindia, y el Pueblo-nación catalán lo es del sur de Europa. Ambos han reivindicado su derecho a la libre determinación para alcanzar una mayor autonomía y la devolución del control de sus territorios ancestrales e instituciones políticas tradicionales. Cada uno conforma un pueblo-nación, con un idioma, instituciones político-jurídicas y tradiciones socioculturales ancestrales propias, y un sentido o percepción subjetiva de

B CLIVATGE, número 8

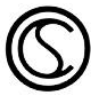


constituir una nación, en gran parte de sus habitantes. Los despojos y expolios que como pueblos-naciones han padecido, se han hecho en fragante violación de pactos preexistentes (vinculantes por su letra, por ius cogens, por pacta sunt servanda, y por el conjunto del derecho internacional público aplicable), no solo sin procesos de consulta previa y consentimiento libre e informado, sin la reparación por los daños causados -en términos de restitución del ejercicio de derechos- ni un mínimo resarcimiento, y sin su participación en los pretendidos beneficios, sino que instrumentados mediante verdaderos genocidios y etnocidios, que se pretenden legitimar, sin más, por el supuesto derecho de conquista (el uti possidetis juris románico).

En efecto, y en la actual fase histórica, estos pueblos naciones -como tantos otros- conformaron un nacionalismo de base, fundamentado en realidades sociocomunitarias objetivables, incontrovertibles y constatables de los rasgos diferenciales de sus sociedades, constituidas de manera espontánea para una misma historia secular compartida, una misma lengua y cultura. Inicialmente, se trató de nacionalismos étnicos-culturales (que no debe confundirse con los raciales), y resultaban la mejor justificación teórica y práctica, a la hora de luchar por sus pueblos y sus libertades nacionales. Precisamente, visualizaban su alta homogeneidad y sentido de pertenencia, cuando mostraban las palmarias especificidades lingüísticas, sociales, culturales, económicas e históricas, que estas etnias presentaban en relación, respecto a lo catalán, con la de los castellanos, los galego-portugueses, los vascos,

B Clivatge, número 8

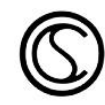


los andaluces; y respecto a lo Mapuche, con la de los huincas, criollos, europeos.

Ahora bien, a consecuencia de los genocidios, despojos y expolios, aculturación y grandes migraciones durante varios decenios, la composición étnica del Principado y los países catalanes, así como la de Puelmapu y Walmapu, se ha visto radicalmente alterada (Camps y Di Nella, 2020; Di Nella, 2018d).

Más específicamente, los principales de estos cambios son:

a) la liquidación de las instituciones políticas propias y las dificultades para restituir su ejercicio, a partir del despliegue de políticas culturales, educativas y de memoria pública de aculturación y asimilacionismo;

b) la expansión de las inversiones extractivistas de grandes corporaciones vinculadas principalmente a los mercados mundiales a través de la subjunción a las metrópolis castellana y criolla, resultando, entre otros, en el despojo y/o expolio de sus territorios, recursos naturales $\mathrm{y}$ humanos, productivos, comerciales e industriales;

c) la modificación de la estructura demográfica, provocados por verdaderos flujos migratorios intra e interterritorial de desplazamiento rural y emplazamiento en sectores periurbanos; $y$ d) la uniformación del sistema de vida y de la cultura, general en el mundo capitalista tras la guerra de 1939-1945, hacia el exitismo, el consumismo y el individualismo, y su impacto en las estrategias de construcción sociocomunitaria de proyectos colectivos de futuro. Así, ante la previsible necesidad de interacción y posibilidad de integración, la conciencia de identidad étnica colectiva entra en

B CLIVATGE, número 8

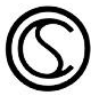


crisis, pues, para poder englobar a todos y todas las recién radicadas en el territorio, para poder aferrarse a la cada vez más inexistente homogeneidad, era preciso renunciar a encuadrar dentro del gentilicio (catalán; mapuche) a los esparcidos por las ciudades del propio espacio geográfico y del mundo que, por causas diversas, ni viven ni trabajan ni sostienen las pautas socioculturales en el territorio.

Por otro lado, y dentro del territorio ancestral, se observarán tasas inusualmente altísimas de nupcialidad o constitución de uniones estables de parejas interétnicas, impactando de forma determinante en la conformación de los grupos de crianza, las descendencias y el sistema de cuidados de la vida humana, a partir de entonces, sumamente diversas (Di Nella, 2018b, 2018c)

La crisis del esencialismo identitario también repercutió en nuevos motivos de recelo e incomodidad -sedimentados sobre los antiguos, de segregación y estigmatización racista como procesos socioeducativos de aculturación escolar-, ante las lenguas autóctonas y su uso y transmisión como lenguas vehiculares habituales.

Otro paso de este proceso -en demérito de la identidad étnica catalana o mapuche y en favor de las impostadas nacionalidades estatocéntricas española y argentina- es el que resulta de la noción de ciudadanía y su asignación según la patriótica división política de los estados coloniales (Quijano, 1991), utilizando el nombre como una simple denominación de una zona geográfica determinada situada al nordeste de la península Ibérica, es decir,

B CLIVATGE, número 8

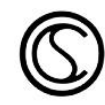


del Imperio español, o dentro de las fronteras de una parte del Virreinato del Río de La Plata, es decir, el Estado colonial argentino. Por último, el sistema patriarcal, extractivista y puramente rentístico que siguió caracterizando las relaciones comerciales y laborales de explotación, indujo también a la articulación de estrategias de resistencia sociocomunitarias interseccionales y situadas, que hicieron converger a los distintos movimientos de derechos humanos, feministas y ambientalistas, con los identitarios de los pueblos naciones.

Esta nueva situación, estaría haciendo tambalear las bases o elementos objetivos anteriormente aducidos de homogeneidad étnica, en que siempre se habían fundamentado no solo el catalanismo y el indigenismo mapuche, sino todo el nacionalismo histórico de los pueblos. La incertidumbre resultante, teórica, ideológica y fáctica, se estaría traduciendo en cinco cuestiones principales que, sin perjuicio de otras, merecen ser especialmente mencionadas.

En primer lugar, la posible apertura de conformaciones de identidades nacionales mas basadas en los elementos subjetivos, volitivos o autopercibidos. Es decir, políticas de pertenencia basadas en la voluntad de reconocerse como parte de un sujeto político colectivo con un proyecto emancipatorio y de futuro en común, sea en estados independientes o en nuevos estados plurinacionales, así como también, y paralelamente, la actualización histórica de los sujetos políticos colectivos representados en los estados capitalistas, coloniales y patriarcales,

B CLIVATGE, número 8

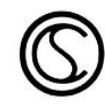


subordinacionistas del emergente entramado de disidencias políticas, sociales y culturales.

En segundo lugar, si el sistema patriarcal, colonial-extractivista y puramente rentístico -que siguió caracterizando las estructurales relaciones comerciales y laborales de explotación- no indujo también a la articulación de estrategias de resistencia sociocomunitarias interseccionales y situadas, que podrían estar haciendo converger en las mujeres que lo protagonizan, a los distintos movimientos de derechos humanos, feministas y ambientalistas, con los identitarios de los pueblos naciones.

En tercer lugar, si la previsible necesidad de interacción y posibilidad de integración de toda la población residente en un determinado espacio físico, es decir, si la conciencia de identidad étnica colectiva, entró o no en crisis, pues, para poder englobar a todos y todas las recién radicadas en el territorio, para poder aferrarse a la cada vez más inexistente homogeneidad, parecería preciso renunciar a encuadrar dentro del gentilicio nacional, a los esparcidos por las ciudades del propio espacio geográfico y del mundo que, por causas diversas, ni viven ni trabajan ni sostienen las pautas socioculturales ni las respectivas caracterizaciones étnicas, en el propio territorio. Mas específicamente, parecería ser que las conformaciones identitarias colectivas fundadas en dicho basamento podrían implicar el reconocimiento de la diversidad e interculturalidad intrínseca de las sociedades actuales, la igualdad material de derechos individuales y colectivos, y la necesidad de una radicalidad democrática, que pretendería poner en el centro la

B CLIVATGE, número 8

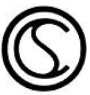


participación política directa en el gobierno y la toma de decisiones, sobre los asuntos que les afectan.

En cuarto lugar, si el alcance y profundidad de las respuestas estatales a los reclamos por la libre determinación, es decir, la forma en que estos pueblos, sus liderazgos sociales y sus intervenciones de acción directa en el espacio público, habrían sido estigmatizadas, rotuladas, criminalizadas y/o reprimidas, observándose los procesos por medio de los cuales pudo eventualmente llegarse -lawfare mediante- a la sistemática persecución mediática-judicial, a la privación de libertad de sus dirigentes, y a la provocación de daños y lesiones gravísimas (incluso el asesinato) de sus militantes sociales.

Y en quinto y último lugar, cabría indagar en la forma de ejercicio del derecho a la protesta social y política de los pueblos naciones, y eventualmente, en una pretendida autosatisfacción de su derecho a la libre determinación mediante el ejercicio de la recuperación y/o ocupación de sus territorios, posesiones e instituciones ancestrales, en desobediencia civil no violenta a decisiones legislativas, ejecutivas o jurisdiccionales emitidas por órganos políticos y judiciales estatocéntricos.

Pero, de todo el presente análisis, no se extraen sino nuevas preguntas. ¿Cómo se configuran y que representan para sus actores $\mathrm{y}$ actrices, sus identidades y pertenencias a sujetos políticos colectivos nacionales no estatales, y las respuestas estatales y sociales a los reclamos por la libre determinación?; a la luz de realidades tan diversas, como los casos de los pueblos naciones mapuche y catalán en Puelmapu y el Principat, ¿Puede 
comprobarse el desarrollo de la cultura, la lengua y la organización jurídica, política, social y económica de un pueblo nación, sin un estado propio?; ¿Puede resolverse socio demográficamente el dilema de integrar una parte de una población, que, pese a coresidir en un mismo territorio que resulta de ocupación ancestral de un pueblo-nación, no ha asumido todavía la realidad nacional como sus ocupantes ancestrales y actuales?.¿El derecho de libre determinación de los pueblos naciones sin estados propios, en estados plurinacionales o bajo estados opresores de su derecho a la existencia diferenciada, han efectivamente cambiado en sus características jurídicas y sociales esenciales, hacia condiciones predominantemente subjetivas-volitivas de pertenencia a esos sujetos políticos colectivos, y nuevas interpretaciones judiciales que lo amplían como derecho de todos los pueblos naciones del mundo? ¿Qué lugar tiene el derecho en todo esto?

Sobre estas cuestiones, cabe abordar un último aspecto que nos resulta del todo relevante, respecto a las perspectivas que aporta el pluralismo jurídico en el análisis y abordaje de estas tensiones e interrogantes.

El pluralismo jurídico surge como una de las corrientes que ha construido un marco teórico concreto para cuestionar estos monismos jurídicos universalizantes y coloniales propios de los estados nación. Desde esta perspectiva, la atención se enfoca en la realidad social, en los seres humanos, en sus relaciones sociales; situación que evidencia una pluralidad de sistemas normativos superpuestos y vigentes, muchos de ellos en conflicto con el derecho estatal.

B CLIVATGE, número 8

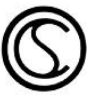


Como veíamos estas "normas otras" o "sistemas de justicia comunitaria", existen en nuestras sociedades más allá de las enunciaciones abstractas del derecho positivo monista, que incluso a veces los reconoce normativamente, por ejemplo, en el caso de los derechos colectivos de los pueblos originarios.

Eugen Ehrlich (2005), uno de los precursores de esta perspectiva, propone la idea del "derecho vivo" para denominar aquellos órdenes normativos paralelos al Estado que surgen espontáneamente en la vida cotidiana como forma de autoregulación y que llegan a ser más importantes para la sociedad que el propio derecho creado y sancionado oficialmente. En esta misma línea, Griffiths afirma que el pluralismo jurídico es un hecho. El centralismo jurídico es un mito, una idea, un reclamo, una ilusión (1995). Ahora bien, que el pluralismo jurídico sea un hecho, no garantiza que esta realidad se materialice, y menos, que exista reconocida en un sistema que la institucionalice. Recordemos que la esencia misma de los estados nación es la de controlar el monopolio de la fuerza.

Por eso, muchos autores, como Vanderlinden (1989), se refieren a un "pluralismo jurídico aparente", donde el derecho estatal decide reconocer la existencia de otros ordenamientos jurídicos para lograr "su afán totalitario" subordinándolos y condicionando su validez. Lo cierto es que, al menos en el caso del "derecho autónomo de los pueblos originarios", los estados nación -en el marco de los derechos humanos- (Convenio 169 y otros) han reconocido al menos este "pluralismo aparente" (Médici, 2016).

B CLIVATGE, número 8

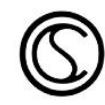


Por su parte, de Sousa Santos (2002) propone, desde una perspectiva crítica, un "diálogo intercultural”, a partir de una "Hermenéutica Diatrópica", buscando "parámetros jurídicosaxiológicos mínimos". Y en este punto, nuevamente nos preguntamos: ¿Qué tipo de diálogo se puede entablar entre las culturas occidentales que reproducen los poderes globales y los pueblos originarios si se encuentran en condiciones de poder tan asimétricas?

Una de las principales críticas que se le ha hecho al pluralismo jurídico es, justamente, su imposibilidad para definir con claridad qué es el derecho. Parecería que no es posible dar, desde la ciencia jurídica, una respuesta única a ello, sin crear abstracciones que intenten delimitar y simplificar lo que, en rigor de verdad, es un fenómeno social necesariamente complejo.

Sin ánimos de caer en un escepticismo radical, creemos que resulta necesario para construir conocimiento crítico en las ciencias jurídicas, habitar las preguntas que venimos esbozando, en relación al poder (Entelman:1999). En este sentido, Dussel (2006: p. 151) sintetiza algunas de las reflexiones que han motorizado hasta ahora estas cuestiones, preguntándose: “¿Se puede cambiar el mundo sin tomar el poder?”. ¿Puede el derecho ser una herramienta para la construcción de una sociedad mejor? Y el mismo autor, se responde: “...En primer lugar, el poder no se "toma" ---como si fuera una cosa, un objeto a la mano, un paquete bien atado. El poder es una facultad de la comunidad política, del pueblo. El poder que pareciera que se "toma" es solamente el de las mediaciones o instituciones del ejercicio delegado del indicado poder

B CLIVATGE, número 8

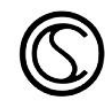


fundamental (...) Es siempre necesario considerar si las instituciones sirven en verdad para satisfacer las reivindicaciones de la comunidad, del pueblo, de los movimientos sociales (...) Es decir, al paquete de las instituciones estatales hay que desatarlo, cambiarle la estructura global, conservar lo sostenible, eliminar lo injusto, crear lo nuevo. No se "toma" el poder en bloque. Se reconstruye y se lo ejerce críticamente." (conf. Dussel, 1994; 2017) A la luz de algunas de las reflexiones expresadas anteriormente, puede observarse a los derechos humanos, como un piso mínimo para garantizar la dignidad humana, pero el horizonte que nos proponemos trazar para romper con las lógicas coloniales de dominación de unos pueblos sobre otros, es mucho mayor.

Si hay algo que aportan las miradas plurales en cualquier ciencia social, es la posibilidad de descentrarnos de las miradas homogeneizantes, normalizadoras y totalizantes, que violentan, discriminan y someten a esas identidades otras. Para Lévinas (1993), "lo otro" es, justamente, plenamente "otro", cuando tiene por consecuencia "fracturar el nosotros, no dejarlo incólumne". La otredad nos disloca, nos desplaza, nos vuelve más humildes y nos infiltra de dudas; nos invita a desconocernos y a abandonar nuestras certezas, entre ellas la de nuestra superioridad.

Es un desafío en estas realidades interculturales e interseccionales, disputar esos reconocimientos en el campo de lo simbólico y en el del poder real donde tal vez la arena sociojurídica sea uno de los escenarios posibles y necesarios.

\section{Conclusiones}

B CLIVATGE, número 8

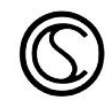


De acuerdo a lo trabajado en este artículo, podemos afirmar que los procesos de descolonizaciones, autodeterminaciones e independencias de los pueblos naciones marginalizados por los Estados coloniales y patriarcales del capitalismo mundial, comparten algunas características comunes.

Por un lado, al grado de insatisfacción que sienten la mayoría de sus miembros por la situación en que se encuentra su pueblo. En efecto, a menudo el Estado es considerado como una institución política que les resulta extraña, de mera anexión y subordinación forzosa de sus pueblos naciones, o bien como una entidad que participa o es cómplice de la extracción, despojo o expolio de sus riquezas, mediante golpes de estado o el despliegue de una estrategia de lawfare mediático-judicial o guerra jurídica contra las personas líderes y referentes de sus pueblos naciones, o contra su posición ideológica, política y social, a través de la represión policial y la persecución político-judicial de la desobediencia civil, la criminalización de sus protestas no violentas y la formulación de un derecho penal del enemigo contra ellos y ellas.

Por otro lado, se observa la autopercepción de pertenencia a un sujeto político colectivo e identitario, que se presenta en un devenir existencial diferenciado, proyectivo, performativo e ilusionante, constitutivos de procesos de resistencia intercultural e interseccional, que conllevan ejercicios autodeterminados de recuperaciones territoriales, posesiones e instituciones políticas ancestrales, en las que son parte destacada, mujeres en desobediencia civil no violenta a decisiones estatocéntricas.

B CLIVATGE, número 8

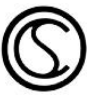


La articulación de sentimientos y realidades similares provoca además la consolidación de movimientos soberanistas de base popular con distintos objetivos políticos, que abarcan desde la reivindicación de espacios de participación política colectiva de libre determinación -como referéndums o consultas vinculantes-, pasando por la delegación de poderes y la autonomía para la conformación de estados plurinacionales, hasta la emancipación política de los estados subordinantes y la subordinación política de los pueblos autodeterministas. Todos ellos, denuncian a su vez, una situación considerada injusta e insatisfactoria, por lo que hace a la extensión y calidad democrática, económica, social, política y de seguridad humana, resultante de la relación entre el Estado y los pueblos naciones así tratados como meras minorías nacionales. Pero, si bien las características de cada Estado -que difieren en cada caso- determinan el estatus de dichos pueblos y las respuestas y tipo de canalización institucional a sus demandas, la fuerza y carácter intercultural e interseccional que adquirieron en los últimos años los movimientos de emancipación política colectiva o nacional, están reconfigurando esas situaciones.

Según los dos casos que hemos comentado -el pueblo nación mapuche y el pueblo nación catalán-, puede observarse que, si bien se trata de estudios aun preliminares, en principio, dos aspectos principales de su actualidad difieren respecto a épocas precedentes. Por un lado, habría una redefinición de la noción de los pueblos naciones, que transitaría, desde la flexibilización de las tradicionales condiciones objetivas de inclusión identitaria (como población de un estado-nación, o raciales, étnicas o lingüísticas-

B CLIVATGE, número 8

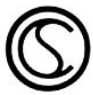


culturales), hacia condiciones predominantemente subjetivasvolitivas de pertenencia a esos sujetos políticos colectivos.

Y por otro lado, la libre determinación de estos pueblos naciones, estaría siendo objeto, en el marco del derecho internacional y constitucional, de nuevas y dinámicas interpretaciones, que ampliarían su alcance y titularidad, desde la autodeterminación externa de los pueblos colonizados ultramarinos, hacia la autodeterminación externa y/o interna de todos los pueblos naciones del mundo.

No obstante, cabrá indagar mas profusamente para dilucidar las causas -y los efectos- que originan y/o producen esta realidad social, y especialmente, desde una mirada comparada a nivel internacional y desde una perspectiva interdisciplinar.

En cualquier caso, las construcciones, representaciones sociales y realidades del derecho de libre determinación de los pueblos naciones sin estados propios, en estados plurinacionales o bajo estados opresores de su derecho a la existencia diferenciada, están mutando en sus características jurídicas y sociales esenciales.

Cabe profundizar en el conocimiento del derecho de libre determinación de los pueblos naciones sin estados propios, en estados plurinacionales o bajo estados opresores de su derecho a la existencia diferenciada, mediante la realización de diversas contrastaciones teóricas y empíricas, como las propuestas para Puelmapu de Walmapu y el Principat de Catalunya y contextualizarlas en los actuales debates y teorizaciones sobre los pueblos y los estados plurinacionales, desde una perspectiva comparada, a nivel internacional. Ello deviene cada vez más, en un

B CLIVATGE, número 8

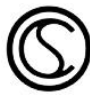


imperativo científico ineludible, para generar conocimiento científico útil y constatar la actual realidad social, económica y jurídica de este fenómeno, así como de sus distintos significados y representaciones en la región.

De bien seguro que, también, contribuirá a promover una mayor sensibilización social respecto a las circunstancias vitales de las militancias sociales del pueblo nación mapuche y del pueblo nación catalán y, por ende, una mayor adecuación de la atención por parte de las instituciones estatales a la hora de implementar medidas de apoyo para evitar o paliar la exclusión social y política que muchas veces conlleva.

Y, finalmente, permitirá la aprehensión conceptual y procesual que posibilitan y/o impiden el ejercicio pacífico - no violento de la libre determinación de estos pueblos, como vías internas y/o externas de relación entre pueblos iguales en derechos. Lo que sí parece cada vez más seguro, es que los grandes protagonistas de esta historia, seguirán siendo los pueblos en acción.

\section{Bibliografía}

Camps, Clara; Di Nella, Dino (2020): Contra hegemonías antirrepresivas. Un estudio de caso de la protesta en Barcelona (2011-2015)". Revista Política y Sociedad". Madrid: España. ISSN: 1130-8001.

Di Nella, Dino (2006): Exclusión Social y Grupos Vulnerables. Barcelona: Copalqui Editorial. pag.128.

B CLIVATGE, número 8

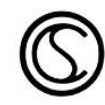


Di Nella, Dino (2011): Para una política universitaria de recuperación de las memorias de luchas por los valores democráticos y la justicia social. Sociologías Plurales. Barcelona: Copalqui Editorial. p87 - 104. isbn 978-84- 936380-7-8.

Di Nella, Dino (2018a): Derechos Humanos y Desigualdades Sociales. REDEA Revista Derechos en Acción. La Plata: Universidad Nacional de La Plata. vol. n8. p54 - 79. ISSN: 25251678.

Di Nella, Dino (2018b): Criminalización, pueblos originarios, y mujeres en zonas urbanas. XIV Seminario sobre Temas actuales y futuros de la sociología del Control Penal. Barcelona: Universidad de Barcelona.

Di Nella, Dino (2018c): Mujeres mapuches en zonas urbanas. Derecho y pueblos originarios en Walmapu. Ciclo sobre Género y feminismos jurídicos. Programa GeDes. Centro de Investigaciones Jurídicas y Sociales. Facultad de DerechoCONICET. Córdoba: UNC.

Di Nella, Dino (2018d): Investigación acción, derecho crítico y pueblos originarios en Puelmapu. Jornadas sobre Derecho crítico y actualidad latinoamericana. La Plata: Universidad Nacional de La Plata.

Di Nella, Dino (2019): Derecho crítico, pueblos originarios y estados. Viedma: UNRN. pag.15. Programa. Disposición ATL $377 / 2019$.

Di Nella, Dino; Giordana, Patricia; Loggiacco, Camila; Arribas, Julián; D’Alfonso, Luis; Almeda, Elisabet; Camps, Clara, (2019): 
Sociología, Derecho y desigualdades sociales. ARXIUS de Ciències Socials. Valencia: UV. vol. 40. P65 - 70. ISSN: 1137-7038. Dussel, Enrique (1994): 1492: El encubrimiento del Otro: hacia el origen del "mito de la modernidad". La Paz, Plural editores.

Dussel, Enrique (2006): 20 tesis de política, por Enrique Dussel. México: Siglo XXI: Centro de Cooperación Regional para la Educaci6n de Adultos en América Latina y el Caribe, 2006, 176 p, - (Sociología y Política) ISBN 968-23-2626-5

Dussel, Enrique (2017): Filosofías del Sur. Descolonización y transmodernidad, México, Ediciones Akal.

Ehrlich, Eugen (2005): “Sociología y Jurisprudencia”, pp. 89-107, en: Eugen Ehrlich, Escritos sobre sociología y jurisprudencia. Madrid: Marcial Pons.

Entelman, R. (1999): Teoría del conflicto. Papeles de trabajo no editados. UBA. Bs.As.

Griffiths, Jhon (1995): "Four Laws of Interaction in circumstances of Legal Pluralism: First steps toward a explanatory theory", pp. 217-227, en: Anthony Allot y Gordon Woodman (eds.), Peoples' Law and State Law: The Bellangio Papers. Forist Publications, Dordrecht.

Lévinas, E (1993): Humanismo del otro hombre. Caparrós Editores. ISBN 978-84-87943-15-7.

Medici, Alejandro (2016): Otros nomos. Teoría del nuevo constitucionalismo latinoamericano. San Luis Potosí-Aguas Calientes. CENEJUS-Maestría en Derechos Humanos UASLP. Quijano, A (1991): “Colonialidad y modernidad/Racionalidad”, en Revista Perú Indígena, 13, 29, pp. 11-29.

B CLIVATGE, número 8

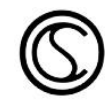


Sousa Santos, Boaventura de (2002): Derecho y emancipación (Pensamiento jurídico contemporáneo, 2). Quito: Corte Constitucional para el Período de Transición.

Vanderlinden, Jacques (1989). "Return to Legal Pluralism: Twenty Years Later", Journal of Legal Pluralism, 28: 149-157.

\footnotetext{
Este texto está protegido por una licencia ReconocimientoCreativeCommons 4.0.
(c) del artículo, los/as autores/as
Usted es libre decompartir - copiar y redistribuir el material en cualquier medio o formato- y adaptar el
documento - remezclar, transformar y crear a partir del material - para cualquier propósito, incluso
comercialmente, siempre que cumpla la condición de:
Atribución: Usted debe reconocer el crédito de una obra de manera adecuada, proporcionar un enlace a la
licencia, e indicar si se han realizado cambios. Puede hacerlo en cualquier forma razonable, pero no de forma tal
que sugiera que tiene el apoyo del licenciante o lo recibe por el uso que hace.
Resumen de licencia - Texto completo de la licencia
} 